\title{
Design and Fabrication of Ocean Water Pumping and Storage System
}

\author{
S.Muthuvel, S.Ananthakrishan, M.Muthukannan
}

\begin{abstract}
Existence of fossil fuels in the near future is not promising because of their depletion at a faster rate and their limited availability. Further, owing to the global warming this energy has drawn global attention towards renewable energy resources. In such a scenario, wave power can cater the power needs of upcoming generations which is green and clean. Our objective is to develop a model which can be used for efficient conversion of wave energy into electrical power. In the present study the concept of buoyancy has been utilized to pump the ocean water and storing it at a higher elevation. From this elevation, the potential energy of water can be converted into kinetic energy for power generation. From the study undertaken, it is observed that the possibility of electricity generation by using this method and on conducting the experiment, it is observed that for a wave power of $150 \mathrm{~W}$, only $10 \%$ of the wave power has been converted and stored in the form of potential energy of water and the remaining unutilized wave power shows that there still exists scope for research work for improving the efficiency of extraction Keywords : Buoyancy, Efficiency, Potential Energy, Wave energy
\end{abstract}

\section{INTRODUCTION}

\section{A. NEED FOR WAVE ENERGY}

Owing to the commitment to reduce the emission of Greenhouse gases and to provide adequate energy, renewable energy resources are unavoidable as an enhancement in energy base. Ensuring that renewable energy is essential in forthcoming situations, quite a few countries have devised stringent policy structure [1]. Wave energy is an economically competitive renewable source. It plays a major role in meeting the energy demand. With the increasing thrust on renewable, wave energy will find an important place in upcoming years [2].

TABLE 2.1

\begin{tabular}{|c|c|c|c|c|c|c|c|}
\hline \multirow{2}{*}{ No } & \multirow{2}{*}{ ocation } & \multicolumn{3}{|c|}{ North-east monsoon } & \multicolumn{3}{|c|}{ South-west monsoon } \\
\cline { 3 - 8 } & $\begin{array}{c}\text { Mean } \\
\text { weight } \\
\text { hav) }\end{array}$ & $\begin{array}{c}\text { Mean } \\
\text { wave } \\
\text { period } \\
(\mathbf{s})\end{array}$ & $\begin{array}{c}\text { Wave } \\
\text { Power } \\
(\mathbf{k W / m})\end{array}$ & $\begin{array}{c}\text { Mean } \\
\text { wave } \\
\text { height } \\
(\mathbf{m})\end{array}$ & $\begin{array}{c}\text { Mea n } \\
\text { wave } \\
\text { period } \\
\mathbf{S}(\mathbf{s})\end{array}$ & $\begin{array}{c}\text { Wave } \\
\text { Power } \\
\text { (kW/m } \\
\mathbf{~}\end{array}$ \\
\hline 1 & $\begin{array}{c}\text { Near } \\
\text { Calcutta }\end{array}$ & 1.33 & 8.00 & 13.85 & 1.95 & 7.65 & 28.80 \\
\hline 2. & $\begin{array}{c}\text { Near } \\
\text { Vizag }\end{array}$ & 1.60 & 6.25 & 15.70 & 2.05 & 8.25 & 33.65 \\
\hline 3. & $\begin{array}{c}\text { Near } \\
\text { Chennai }\end{array}$ & 1.55 & 5.85 & 13.45 & 1.70 & 5.80 & 16.60 \\
\hline 4. & $\begin{array}{c}\text { Near } \\
\text { Mumbai }\end{array}$ & 1.00 & 5.00 & 4.90 & 2.65 & 6.95 & 47.00 \\
\hline
\end{tabular}

Revised Manuscript Received on December 30, 2019.

* Correspondence Author

S.Muthuvel*, Mehcanical Engineering, Kalasalingam Academy of Research and Education, Virudhunagar, India. Email:S.Muthuvel@klu.ac.in

S.Ananthakrishn, Mehcanical Engineering, Kalasalingam Academy of

Research and Education, Virudhunagar, India. Email: ananthakrishnan@klu.ac.in.

M.Muthukannan, Mehcanical Engineering, Kalasalingam Academy of

Research and Education, Virudhunagar, India.

Email:mmk.mech59@gmail.com

\section{B. WAVE ENERGY BASICS}

Wave energy comes from the interaction between the winds and surfaces of oceans. Ocean wave is due to the periodic to and fro, up and down motion of water particles in the form of progressive waves. The waves originate in different parts of the ocean and travel towards the shore. The energy available varies with the size and frequency of waves. Ocean waves possess both potential energy and kinetic energy [3]. It is estimated that about $50 \mathrm{~kW}$ of power is available for every meter width of true wave front. The wave height depends upon velocity of the wind, depth of the ocean, and contour of the shore.

\section{Advantages OF WAVE Energy}

- It is a clean, renewable energy source.

- Wave power devices do not require large land masses.

- The action of large waves minimizes erosion.

- Relatively pollution free.

\section{ADVANTAGES OF WAVE ENERGY}

- Lack of dependability.

- Relative scarcity of accessible sites of large wave activity.

- Construction of conversion devicesis complicated.

- Devices have to withstand enormous power of stormy seas.

- There are unfavorable economic factors such as large capital investment

- Costs of repair, replacement and maintenance.

\section{LITERATURE REVIEW}

A. Wave energy sites in India

GulfofKutchandKhambhatarepotential locationin Arabic seawhichiswestwesterntoIndiancoastalregion. Maximum tidal range is between $11 \mathrm{~m}$ and $8 \mathrm{~m}$ and average tidal range is $6.77-5.2 \mathrm{~m}$ [5]. The economic tidal power range in India is 8000-9000 MW. $7000 \mathrm{MW}$ power generation from the Gulf of Khambhat, 1200 MW capacity plant located in the Gulf of Kutch and approximately 100 MW capacity power generation in Sundarbans [6]. Wave energy potential on Indian coasts is shown in Table 2.1

\section{EXISTING WAVE ENERGYPROJECTS}

\section{A. WAVE BARRAGES}

The rise and fall of tides in an estuary (river mouth into which the tide flows from sea) can be made use of to drive specially designed low head water turbines. These turbines can operate even at a very low head of $0.5 \mathrm{~m}$. During high tide, the dam allows the sea water to get ahead of the basin through sluice gate as shown Figure1. 
The water stored in the basin will be used to run turbines at fewer waves. The ebb and flow of the tide is used to happen at low tide. The water from the basin can be used to turn a turbine shaft thereby potential energy is converted into mechanical [7].

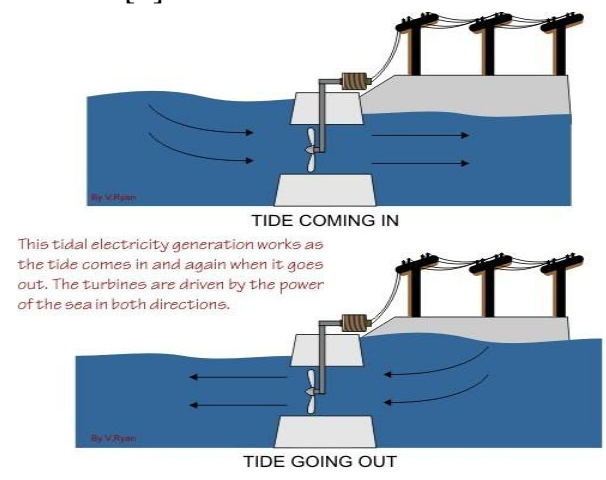

Fig. 1: Tidal, dam and Basin

\section{B. WAVE BARRAGES}

Electricityisgenerated inmarineturbinesby meansof wavecurrentflows. Wavecurrentshelpstodrivetheturbine rotorblades[8].ThemarinepropellerisshowninFigure2.

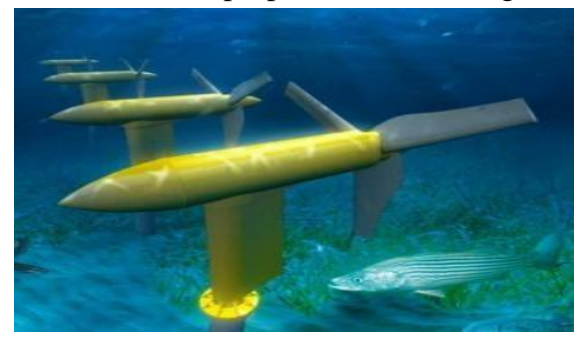

Fig 2.2 Marine propeller

\section{OSCILlating WATER COLUMN}

An oscillating water column (OWC) is an wave energy converting mechanism into electrical energy which can be mounted onto land particularly on rocky shores. OWC consists of a wave capture chamber, a platform, a lip, wing walls, and an air chamber.This principle is used in Vizhinjam power plant in Kerala. The concept of OWC is shown in Figure 3.

\section{FACTORS AFFECTING WAVEENERGY}

\section{A. Wind Speed}

With the increase in wind speed, there is an increase in wave energy. The amplitude of the waves depends on wind speed.

\section{B. Depth of ocean water}

The greater the depth of ocean waters the higher the wave velocity. Very large energy fluxes are available in deep ocean waves which has unlimited power and energy.

\section{Effective pitch value}

It is the uninterrupted distance on the ocean over which the wind can blow before reaching the point of reference. The larger the distance, higher is the wave energy. This distance may vary from 5 $\mathrm{km}$ to $45 \mathrm{~km}$.

\section{PROJECT CONCEPT ANDWORKING}

\section{A. Introduction}

The present project work of ocean water pumping and storage utilizes the concept of buoyancy force of the waves to pump water to upper height for storage.

\section{B. Reason for utilization of buoyancy}

An upward force applied by a fluid, which resists the load of a submerged entity is called Buoyancy. The product may be either low density than the fluid or is formed suitable so that the energy can stay the object floating. This phenomenon is called buoyancy [3].

The concept of wave barrages, marine propellers and oscillating water column shown in Figure 3 had several negative issues. In case of wave barrages and marine propellers, aligning the turbine blades according to the direction of wave current requires an extra yaw mechanism and they have negative effect on marine life. Trapping atmospheric air becomes difficult in oscillating water column, if sea level increases. Thus buoyancy concept was found to eliminate such negative issues and comparatively efficient.

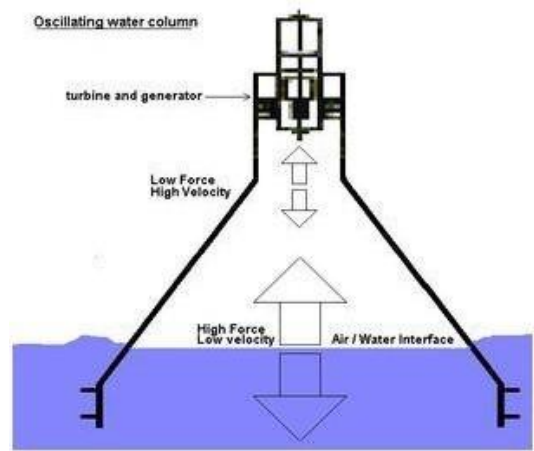

Fig.3: The concept of $\mathrm{OWC}$

\section{Working of ocean water pumping}

The design of assembled model is shown in Figure4.

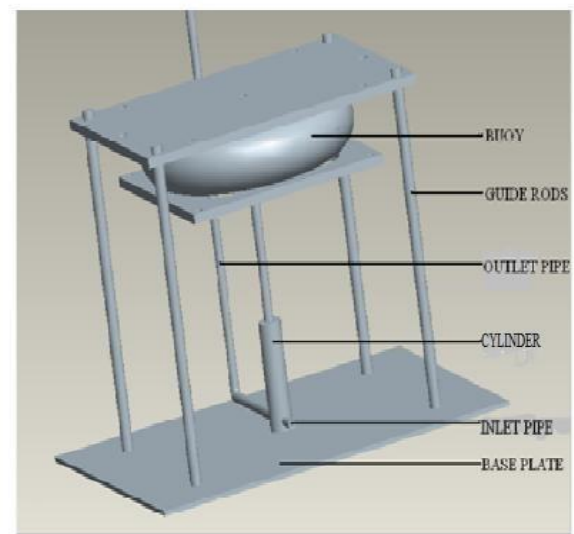

Fig.4: Pro E Design of assembled model

Due to the rise and fall of the waves, the buoy will move up and down. The buoy is connected to the piston of a hydraulic pump. The pump has an inlet valve and an outlet valve. During the rise of the waves, the piston moves up and creates a low pressure area below it in the cylinder. The pressure of water surrounding the cylinder is higher than the pressure inside the cylinder and water flows from high to low pressure area. During the fall of the waves, the piston comes down and the total force of the buoy acts on the water trapped in the cylinder. The exit of water through the inlet valve is arrested by using a non - return valve. The water is pushed out through the outlet valve with great pressure. This pressure causes the water to move upwards against the gravity, up to a height of 5.12 meters. At this height a storage tank is kept and the pumped ocean water is stored. The return of pumped water into the cylinder is arrested by using another non - return valve in the outlet pipe. 


\section{A. Base plate and guide rods}

Thedesign ofindividualcomponentsis asfollows. The base plate is a rectangular plate of $s i z e 100 \times 80 \mathrm{~cm}$. Guide rods are fixed to the base plate to guide the movement of the buoy in up and down direction. The design of the base plate and guide rods is shown in Figure 5

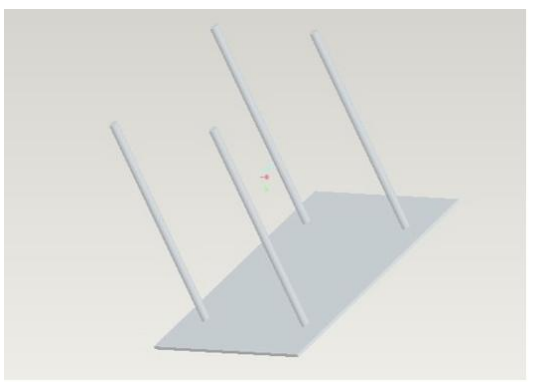

Fig. 5: Pro E design of base plate and guide rods

\section{B. Cylinder and piston}

The internal diameter of the cylinder is $5 \mathrm{~cm}$ and external diameter is $6 \mathrm{~cm}$ and its height is $20 \mathrm{~cm}$. The diameter of piston is $5 \mathrm{~cm}$ and the diameter of piston rod is $3 \mathrm{~cm}$ and its height is $60 \mathrm{~cm}$. The design of cylinder and piston is shown in Figure 6.

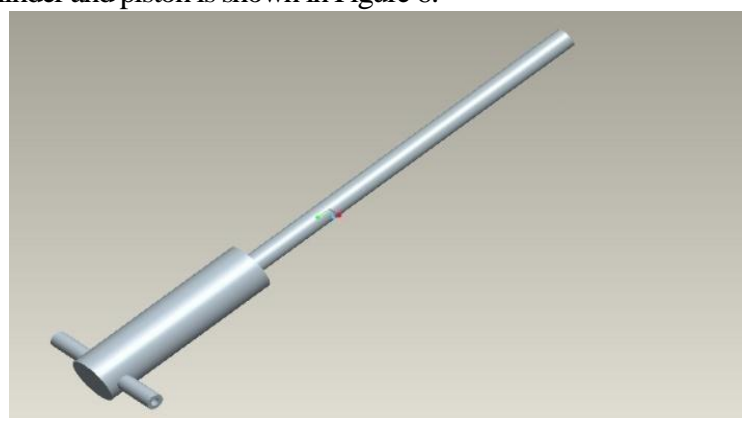

Fig. 6: Pro E design of cylinder

\section{Buoy(Float)}

The buoy consists of two plates with a rubber tube in between [10]. The top plate is of size $77.5 \times 55 \mathrm{~cm}$ and bottom plate is $55 \times 55 \mathrm{~cm}$. The diameter of the tube is $57.5 \mathrm{~cm}$. The design of buoy is shown in the Figure 7.

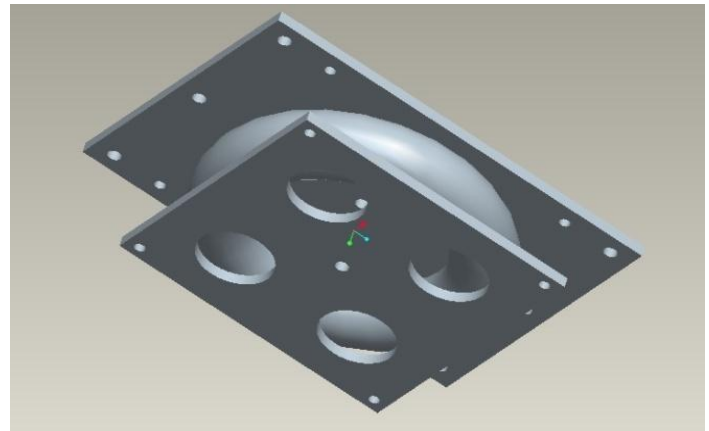

Fig. 7: Pro Edesign of buoy

\section{A. Condition for buoyancy}

Weight of the system < Buoyancy force

Weight of the system = Mass of all parts of the system $\mathrm{x}$

Acceleration due to gravity

$$
\begin{aligned}
& =30 \times 9.81 \\
& =294.3 \mathrm{~N} .
\end{aligned}
$$

Buoyancyforce $=$ Volume of buoy $\mathrm{x}$ Density of water $\mathrm{x}$ Acceleration due to gravity.

$$
\begin{aligned}
& =\left(\pi \times 0.4^{2} \times 0.3\right) \times 1000 \times 9.81 \\
& =1479.3 \mathrm{~N} .
\end{aligned}
$$

Therefore the weight of the system is less than the buoyancy force.

\section{B. Wave fume parameters}

The Proposed model is going to be tested in the wave flume facility in Anna University.
1. Wave velocity $=1.5 \mathrm{~m} / \mathrm{s}$
2. Wave height $\quad=8 \mathrm{~cm}$
3 . Time period of consecutive waves $=2 \mathrm{~s}$.

C. Water pumping calculation

The Proposed model is going to be tested in the wave flume facility in Anna University

Since the maximum wave height is $8 \mathrm{~cm}$ in the wave flume, the maximum displacement attained by the piston will be

$8 \mathrm{~cm}$.

Working area of the piston

$$
\begin{aligned}
& =\pi \times \mathrm{r}^{2} \\
& =\pi \times .025^{2} \\
& =0.0019625 \mathrm{~m}^{2}
\end{aligned}
$$

Pressure inside the cylinder

$$
\begin{aligned}
& =\text { force } / \text { area } \\
& =300 / 0.00196 \\
& =1.52 \text { bar. }
\end{aligned}
$$

Volume of piston displacement $\quad=\pi \times \mathrm{r}^{2} \times \mathrm{h}$

$$
\begin{aligned}
& =\pi \times .025^{2} \times .08 \\
& =0.0001568 \mathrm{~m}^{3} .
\end{aligned}
$$

Volume of water displacement $\quad=0.0001568 / 2$

$$
=0.0000784 \mathrm{~m} 3 / \mathrm{s}
$$

Inner diameter of connecting pipe $=1 \mathrm{~cm}$.

Cross sectional area of pipe $\quad=\pi \times .005^{2}=0.000078 \mathrm{~m}^{2}$

Quantity of discharge $=$ area $\times$ velocity

$$
\begin{aligned}
& =0.0000784 \\
& =0.000078 \times \text { velocity }
\end{aligned}
$$

Velocity at inlet of the connecting pipe $=1 \mathrm{~m} / \mathrm{s}$. By Bernoulli's equation,

$$
\begin{aligned}
& \mathrm{P}_{1} / \mu \mathrm{g}+\mathrm{v}_{1}^{2} / 2 \mathrm{~g}+\mathrm{z}_{1}=\mathrm{P}_{2} / \mathrm{\rho g}+\mathrm{v}_{2}^{2} / 2 \mathrm{~g}+\mathrm{z}_{2} \\
& \frac{1.52}{9810}+\frac{1^{2}}{19.62}+0=\frac{1.03}{9810}+0+z_{2} \\
& \quad \text { (since exit velocity and hexd at inlet is zero) } \\
& 1.55 \times 10^{-4}+0.05=1.15 \times 10^{-4}+z_{2}
\end{aligned}
$$

Hence $\mathrm{z}_{2}=5.05 \mathrm{~m}$. From the data it is showed that water can be raised to the height of 5.05. Efficiency of utilization from wave power:Available power on the generated wave, where $\rho$ is the density of water, $g$ is the acceleration due to gravity, $\mathrm{H}$ is the wave height from trough to crest and $\mathrm{T}$ is the time period between two consecutive waves.

$$
P=\frac{1}{\text { an }} \times 1000 \times 9.812 \times .082 \times 2=6.13 \mathrm{~W}
$$

Power generated on the experimental setup, $\mathrm{P}=0.33 \mathrm{~W}$

Potential energy collected on container per second

$=($ mass of water delivered per second in the container $\mathrm{x}$ acceleration due to gravity $\mathrm{x}$ height of the container from

$$
\text { ground) }
$$

$$
\begin{aligned}
& =0.014 \times 9.81 \times 2.4 \\
& =0.33 \mathrm{~W}
\end{aligned}
$$


Therefore, Efficiency of newly developed device, $\eta=$ $\left(\mathrm{P}_{\text {generated }} / \mathrm{P}_{\text {available }}\right) \times 100 \%$

$$
\begin{aligned}
& =(0.33 \mathrm{~W} / 6.13 \mathrm{~W}) \times 100 \\
& =5.38 \%
\end{aligned}
$$

\section{FABRICATION}

\section{A. Material selection}

The first step in the fabrication is to select the materials for individual components. The foundation for the complete model is the base plate. It should withstand the dead load and working pressures of the model. The cylinder should withstand the pressure exerted by the piston. As the complete model is in contact with water, all the components must be corrosion resistant. So the following materials were found to efficiently suit our requirements.

1. Base plate - Mild steel

2. Guide rods - Stainless steel

3. Cylinder - Acrylic tube

4. Piston - PVC

5. Piston rod - Stainless steel

6. Buoy - Acrylic plates and rubber tube

7. Bolts, Nuts and Clamps - Stainless steel

\section{B. Procedure}

Raw base plate was procured and cut to the required size $(100 \times 80 \mathrm{~cm})$ withthe help of shearing machine.Markings were made on the base plate for guide rods and cylinderposition. The base for the guide rods were made by turning, drilling andinternal threading operations. The base for guide rods was fixed to the base plate by welding. The guide rods were inserted into their bases and bolted firmly. Thebolt and the base were welded. An extra bolt was provided to increase the rigidity. Assembled view of base plate and guide rods are shown in fig 5.1

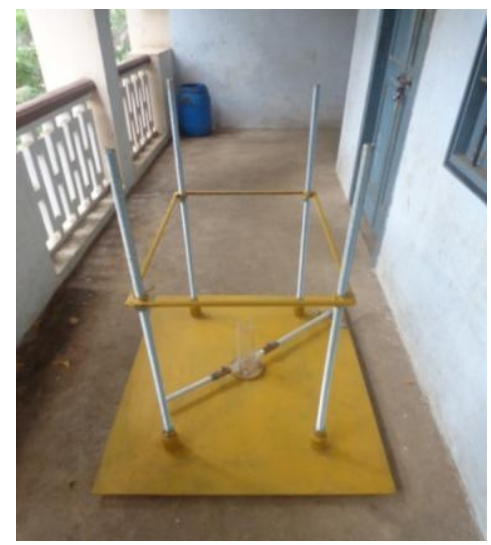

\section{Fig 5.1 Assembled view of base plate and guide rods}

\footnotetext{
Forthecylinder,thestandard5cminnerdiameteracrylic tube was procured andcuttorequiredlengthwithcutter. Twoholesweredrilledinthecylinderatthebottom with internal threads for inletandoutletvalves.Forvalves, the standard $1 \mathrm{~cm}$ inner diameter acrylic tubes were procured andthreadedbothsides.

Thevalveswere affixed tocylinderandnon-returnvalves (NRV)areattached.Cylinderwasfixedtothebaseplate

withflangeandbolts.Araldite was usedtoincreasethe
}

firmness.PistonwasmadeofPVC.PVCismachinedby turning operations to reachanouterdiameterof $5 \mathrm{~cm}$. Internalthreading wasmadeatthetopofthepistonby

tapping.Pistonrodwasinsertedintothethreadedholeon thetop ofthepiston and bolted.Assembledviewofcylinder andNRVisshowninfig5.2.

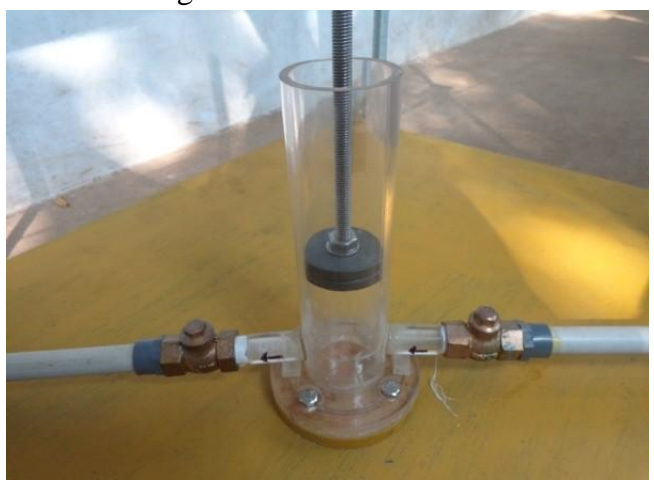

Fig. 5.2 Assembled view of cylinder and NRV

For buoy, a large acrylic sheet was procured. It was cut into required size by cutting machine. Markings were done on the acrylic sheet for drilling holes. By manual drilling, holes were drilled on the acrylic sheet for inserting guide rods and bolting. A PVC bush was inserted into the guide holes and bolted. A rubber tube was inflated and kept between the acrylic plates and bolted. Assembled view of buoy is shown in figure 5.3.

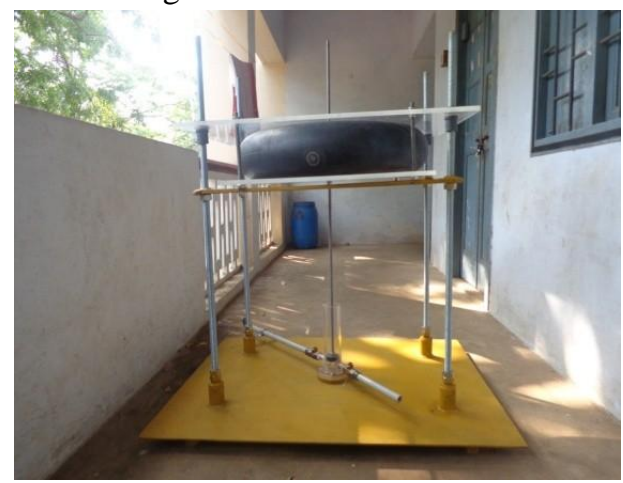

Fig 5.3 Assembled view of model

\section{CONCLUSION}

The ocean water pumping system has been designed and fabricated. The project utilizes the ocean waves which has unlimited energy and also available in abundance. It does not need any fuel which reduces the fuel cost.. Thus the project will help to meet the growing concern for the increasing energy demand by harnessing wave energy.

In future the optimization will be done in buoy and other parts of the system in order to increase the efficiency even better and also it further requires research on the installation methods and designing based upon the varying wave parameters.

\section{REFERENCES}

1. N. L.Panwar, S. C. Kaushik, and S. Kothari, "Role of renewable energy sourcesin environmental protection: A review," Renew. Sustain. Energy Rev., vol. 15, no. 3, pp. 1513-1524, 2011. 
2. S. Nair, A. Hamrah, R. B. Raj, M. Kathiresan, and T. Mukundan, "Fabrication of organic thin filmtransistors for applicationin flexible sensors," AIP Conf. Proc., vol. 2082, no.March, pp. 22-25, 2019.

3. A. Hussain, S. M. Arif, and M. Aslam, "Emerging renewable and sustainable energytechnologies:State ofthe art," Renew. Sustain. Energy Rev., vol. 71, no. December 2016, pp. 12-28, 2017.

4. J.Mohtasham, "Review Article-Renewable Energies,"Energy Procedia, vol. 74, pp. 1289-1297, 2015.

5. Sen, S. Ganguly, A. Das, J. Sen, andS. Dey, "Renewable energy scenarioin India: Opportunities and challenges," J. African Earth Sci., vol. 122, pp. 25-31, 2016.

6. The Sundarban Biosphere Reserve, India, using geospatialtechnology," Environ. Earth Sci., vol. 78, no.10, pp. 1-22, 2019.

7. D. Khojasteh, D. Khojasteh, R. Kamali, A. Beyene, and G. Iglesias, "Assessment of renewable energy resources in Iran; witha focus on wave and tidal energy," Renew. Sustain. Energy Rev., vol. 81, no. December 2016, pp. 2992-3005, 2018.

8. R. Muscari, A. DiMascio, and R. Verzicco, "Modeling of vortex dynamics inthe wake ofa marine propeller," Comput. Fluids, vol. 73 , pp. 65-79, 2013.

9. A.F. O. Falcão and J. C. C. Henriques, "Oscillating- water-column wave energy converters and airturbines: A review," Renew. Energy, vol. 85, pp. 1391-1424, 2016.

10. J. Wang, Z. Wang, Y. Wang, S. Liu, and Y. Li, "Current situation andtrend of marine data buoy and monitoring networktechnology of China," Acta Oceanol. Sin., vol. 35, no. 2, pp. 1-10, 2016.

\section{AUTHORS PROFILE}

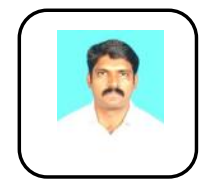

S.Muthuvel graduated from the Madurai Kamarajar University in the year 2000 with Bachelor of Engineering (Mechanical Engineering) and Masters from National Insititute of Technology in the year 2005. He has four years of industrial experience in Tata consultancy Engineering. He was member of ISTE. His expertise is thermal engineering and Passive cooling applications.

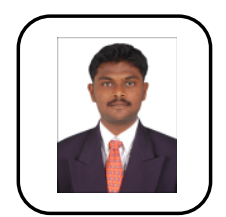

S.Anandhakrishnan graduated from College of guindy, Anna University in the year 2013 with Bachelor of Engineering (Mechanical Engineering) and Masters from PSG College of Technology in the year 2016.His expertise in design.

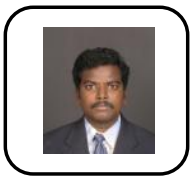

M.Muthukannangraduated from the Madurai Kamarajar University in the year 2004 with Bachelor of Engineering (Mechanical Engineering) and Masters from PSG College of Technology in the year 2008. He has industrial experience of 1 year. He was member of ISTE. His expertise is Heat transfer and Computational Fluid Dynamics. 